\title{
ValuedCare program: a population health model for the delivery of evidence-based care across care continuum for hip fracture patients in Eastern Singapore
}

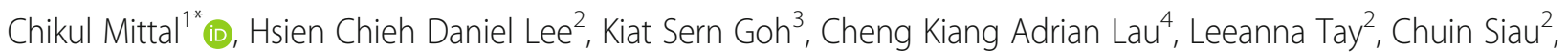
Yik Hin Loh ${ }^{5}$, Teck Kheng Edward Goh ${ }^{6}$, Chit Lwin Sandi ${ }^{7}$ and Chien Earn Lee ${ }^{8}$

\begin{abstract}
Background: To test a population health program which could, through the application of process redesign, implement multiple evidence-based practices across the continuum of care in a functionally integrated health delivery system and deliver highly reliable and consistent evidence-based surgical care for patients with fragility hip fractures in an acute tertiary general hospital.

Methods: The ValuedCare (VC) program was developed in three distinct phases as an ongoing collaboration between the Geisinger Health System (GHS), USA, and Changi General Hospital (CGH), Singapore, modelled after the GHS ProvenCare ${ }^{\circledast}$ Fragile Hip Fracture Program. Clinical outcome data on consecutive hip fracture patients seen in 12 months pre-intervention were then compared with the post-intervention group. Both pre- and postintervention groups were followed up across the continuum of care for a period of 12 months.

Results: VC patients showed significant improvement in median time to surgery (97 to $50.5 \mathrm{~h}$ ), as well as proportion of patients operated within $48 \mathrm{~h}$ from hospital admission (48\% from 18.8\%) as compared to baseline pre-intervention data. These patients also had significant reduction ( $p$ value $<0.001$ ) of acute inpatient complications such as delirium, pneumonia, urinary tract infections, and pressure sores. VC program has shown significant reduction in median length of stay for acute hospital (13 to 9 days) as well as median combined length of stay for acute and sub-acute rehabilitation hospital (46 to 39 days), thus reducing the total duration of hospitalization and saving total hospital bed days. Operative and inpatient mortality, together with readmission rates, remained low and comparable to international Geriatric Fracture Centers (GFCs).

Conclusion: The implementation of VC methodology has enabled consistent delivery of high-quality, reliable and comprehensive evidence-based care for hip fracture patients at Changi General Hospital. This has also reflected successful change management and interdisciplinary collaboration within the organization through the program. There is potential for testing this methodology as a quality improvement framework replicable to other disease groups in a functionally integrated healthcare system.
\end{abstract}

Keywords: Value-based care, Population health, Hip fracture, Singapore, Evidence-based medicine, ValuedCare, Integrated care, Care pathways

\footnotetext{
*Correspondence: Chikul_mittal@cgh.com.sg; Mittal.chikul@gmail.com

${ }^{1}$ Clinical Services, Level 2, Changi General Hospital, 2 Simei Avenue 3,

Singapore 529889, Singapore

Full list of author information is available at the end of the article
}

(c) The Author(s). 2018 Open Access This article is distributed under the terms of the Creative Commons Attribution 4.0 International License (http://creativecommons.org/licenses/by/4.0/), which permits unrestricted use, distribution, and reproduction in any medium, provided you give appropriate credit to the original author(s) and the source, provide a link to the Creative Commons license, and indicate if changes were made. The Creative Commons Public Domain Dedication waiver (http://creativecommons.org/publicdomain/zero/1.0/) applies to the data made available in this article, unless otherwise stated. 


\section{Background}

Hip fractures cause significant morbidity and mortality in the elderly. Although the mainstay of treatment is surgical fixation or replacement, these patients are often vulnerable with complex medical, functional, psychosocial issues requiring a multidisciplinary approach to maximize their recovery [1-7].

Singapore is one of the most rapidly aging countries in Asia. The prevalence of adults older than 65 years is set to rise from $9.9 \%$ in 2012 to about $20 \%$ in the next 20 years $[8,9]$. The International Osteoporosis Foundation's 2009 Asian Audit Report states that the incidence of hip fractures in Singapore is expected to increase from 1300 in 1998 to 9000 per annum by $2050[9,10]$. Singapore enjoys a unique healthcare ecosystem, where acute episodic care is largely delivered at acute hospitals [AHs (tertiary care corporatized hospitals, fully owned by the government)], while community hospitals (CHs) play an important role in the postacute rehabilitative care for elderly patients, particularly those with comorbidities. Therefore, the main functions of the community hospitals are to provide geriatric assessment and rehabilitation and ongoing continuation of medical or nursing treatment (sub-acute care) [11]. $\mathrm{AH}$ and $\mathrm{CH}$ could be independent or vertically integrated co-located organizations with varying degrees of functional or normative integration based on geographical proximities.

$\mathrm{AH}$ and $\mathrm{CH}$, together with long-term care facilities and community care resources as well as primary care, aim to work together as a Regional Health System (RHS) to provide seamless integrated care [11-13].

The success of care pathways for hip fractures has been variable [11]. In spite of existing inpatient pathways for patients admitted with hip fractures in Singapore AHs, there are inter- and intra-hospital variations in the level of coordination between different clinical teams (e.g. geriatricians, orthopaedics, anaesthetists, emergency physicians, case managers and therapists), length of stay, time to surgery and bill sizes, often causing fragmentation of care. Additionally, most reported studies take into account only the AH admissions. There is a paucity of data on the effectiveness/ long-term outcomes of hip fracture programs across the entire care continuum.

Thus, our aim was to create and test a population health program which could, through the application of process redesign, implement multiple evidence-based medical practices across the continuum of care in an integrated delivery system and deliver highly reliable and consistent evidence-based care for episodic surgical interventions.

Ethical clearance was obtained by the Institutional Review Board (IRB) for this study.

\section{Methods}

\section{Setting}

Changi General Hospital (CGH) is a 1000-bed tertiary acute hospital (AH) located in eastern Singapore. It is part of an Integrated Regional Health System (Eastern Health Alliance) with formal partnerships and a range of healthcare organizations which have a specific focus along the healthcare continuum. St. Andrews Community Hospital $(\mathrm{SACH})$ is one of such partners with a shared purpose of providing seamless integrated care for eastern Singapore [13].

\section{The ValuedCare methodology}

Langley et al. [14] had shown quality improvement through process redesign, and Nolan et al. [15] introduced the concept of high reliability within healthcare. Geisinger's ProvenCare ${ }^{\oplus}$ [16] had successfully combined both approaches to help address the gap between recommendations and actual clinical practice. In 2014, the ValuedCare (VC) Hip Fracture Program was launched as an ongoing collaboration between the Geisinger Health System (GHS), USA, and Changi General Hospital, Singapore; modelled after the GHS ProvenCare ${ }^{\circ}$ Fragile Hip Fracture Program [14-21].

The VC Hip Fracture Program was developed in three distinct phases:

- Care gap analysis;

- Process redesign;

- Execution: implementation, capability building, monitoring of compliance and evaluation.

\section{Care gap analysis}

Facilitated discussions of internationally published evidence and local practice were essential in achieving physician consensus and translating recommendations into local clinical application. To facilitate change management in a multidisciplinary team, clinical champions (senior clinicians and domain experts) were appointed from stakeholder departments including orthopaedics, geriatrics, case management, nursing, allied health and emergency medicine as well as anesthesiology. Clinical champions were actively involved in appraising the evidence together. Level I and II evidence were chosen and discussed, to select 23 best practice elements (BPEs) across the care continuum. Figure 1 summarizes the 23 BPEs; operational definitions and measurable elements were defined for each of the BPEs to ensure compliance.

\section{Process redesign}

Our process redesign began with the fundamental principle of designing and delivering patient-centric care consistently across the entire care continuum. A 


\begin{tabular}{|c|c|c|c|c|}
\hline A\&E & Pre-Operative Period & Post-Operative Period & Discharge & Post-Discharge \\
\hline $\begin{array}{l}\text { 1. Pain protocol } \\
2 . \text { X-ray } \\
\text { dem onstrating } \\
\text { fracture (including } \\
\text { Hip and knee) on } \\
\text { admission } \\
\text { 3. Lab studies to } \\
\text { include complete } \\
\text { blood count, INR, } \\
\text { Type \& Screen, BMP, } \\
\text { ferritin, transferrin, } \\
25 \text { hydroxyitam in } \\
\text { D, TSH, urinalysis }\end{array}$ & $\begin{array}{l}\text { 4. Ortho clerking and } \\
\text { consult } \\
\text { 5. Pre-fracture } \\
\text { assessment } \\
\text { 6. Bowel protocol } \\
\text { 7. Delirium screening } \\
\text { 8. Antibiotics within } \\
60 \text { mins of incision } \\
\text { 9. Surgery within } 48 \text { hrs } \\
\text { 10. Case management } \\
\text { consult }\end{array}$ & $\begin{array}{l}\text { 11. X-ray \& lab } \\
\text { investigations } \\
\text { 12. Discontinue antibiotics } \\
\text { within } 24 \text { hrs unless } \\
\text { indicated } \\
\text { 13. Ortho-geriatrician } \\
\text { consult } \\
\text { 14. } 1^{\text {st }} \text { (Post-Operative Day) } \\
\text { POD WBAT (Weight bearing } \\
\text { as Tolerated) order } \\
\text { 15. } 1^{\text {st }} \text { POD Physiotherapy } \\
\text { (PT) commence } \\
\text { mobilisation }\end{array}$ & $\begin{array}{l}\text { 16. Finalise discharge } \\
\text { plan with patient / } \\
\text { caregiver by } 2^{\text {nd }} \text { POD } \\
\text { 17. Discharge } \\
\text { instructions (WBAT, } \\
\text { mobility, functional, } \\
\text { wound care) }\end{array}$ & $\begin{array}{l}\text { 18. Compliance to } \\
\text { follow-up visits } \\
\text { 19. Wound check } \\
\text { 20. Parker } \\
\text { Mobility } \\
\text { 21. Modified } \\
\text { Barthel Inder } \\
\text { 22. Quality of life } \\
\text { Score (EQ-5D) }\end{array}$ \\
\hline
\end{tabular}

23. DVT Prophylaxis and Skin Assessment

Fig. 1 ValuedCare 23 best practices from A\&E to inpatient stay and post-discharge care

multidisciplinary team led by the clinical champions worked together to hardwire the evidence-based BPEs into clinical workflows, prevent duplication of services and variability of care, and to manage the health of this patient population, since many of them have multiple co-morbidities. Our intent was to further encourage a productive interaction between informed, activated patients and prepared proactive staff. The team studied current process flows for each discipline and utilized value stream mapping to visualize how multiple disciplines should interact in an integrated pathway.

The finalized care pathway and BPEs were hardwired using information technology and electronic health records (EHR) to enable behavior change and provide decision support, as well as facilitate ease of information diffusion across multiple settings. The aim was to make best care fall within the path of least resistance and in-build a system to minimize unwarranted variations in care.

The care process entailed visualizing the patient journey starting from presentation at the accident and emergency department (A\&E), acute hospital admission, community hospital admission and care transition into the community as well as post-discharge specialty care to assess long-term functional outcomes and start secondary prevention.

\section{Execution}

Quality improvement and governance components were deliberately added into the program structure to assure compliance to each of the process elements. All participants knew that compliance with each of the process elements, both as a team and as individuals, would be tracked and real-time feedback given. Due to the strong measurement strategy, any process defect was quickly identified and a focused redesign was immediately started.

For clinical governance, a clinical core team was created to lead the redesign of the care process and implementation of reliable evidence-based care. The multidisciplinary clinical core team monitored compliance to BPEs, information diffusion to ground staff and issues faced on the ground. This team was also responsible for the ownership of clinical outcomes.

The team conducted continuous quality improvement (QI) focus biweekly meetings, where members from different disciplines voice out issues faced on the ground and brainstormed to find solutions and build consensus for immediate remedy or proposed plans for action to address deficiencies in care processes or health outcomes. These meetings worked as mini-PDSA (PlanDo-Study-Act) cycles and spearheaded the short-term quality improvements within the program. Table 1 
Table 1 Key process improvements achieved through ValuedCare methodology

\begin{tabular}{|c|c|c|}
\hline Objectives & Pre-intervention & Post-intervention \\
\hline \multirow[t]{4}{*}{$\begin{array}{l}\text { Early surgery within } \\
48 \mathrm{~h}\end{array}$} & $\begin{array}{l}\text { Anaesthetic guidelines appended in pathway not used } \\
\text { routinely }\end{array}$ & $\begin{array}{l}\text { Orthopaedic team identifies and lists patients for early } \\
\text { surgery with the use of anaesthetic checklist upon clerking }\end{array}$ \\
\hline & $\begin{array}{l}\text { Investigations ordered by the accident and emergency } \\
\text { department (A\&E) and the orthopaedics team, resulting } \\
\text { in missing or duplicate orders }\end{array}$ & $\begin{array}{l}\text { A\&E doctor commences investigation order set to facilitate } \\
\text { orthopaedics team in review and listing for surgery }\end{array}$ \\
\hline & Delayed review of early surgery rates & $\begin{array}{l}2 \text { weekly multi-disciplinary review of early surgery rates and } \\
\text { documentation of reasons for delayed surgery }\end{array}$ \\
\hline & $\begin{array}{l}\text { No dedicated high dependency (HD) beds for } \\
\text { post-operative care, causing surgical delays }\end{array}$ & 3 dedicated HD beds for ValuedCare patients \\
\hline \multirow{2}{*}{$\begin{array}{l}\text { Reduce } \\
\text { complications }\end{array}$} & DVT prophylaxis starts from ward admission & DVT prophylaxis starts from A\&E \\
\hline & $\begin{array}{l}\text { Ad hoc prescribing of pain, bowel medications, } \\
\text { supplements and antibiotics }\end{array}$ & $\begin{array}{l}\text { Standardized electronic orders used by orthopaedics team } \\
\text { Medications reviewed by ortho-geriatrician and pharmacist }\end{array}$ \\
\hline \multirow{2}{*}{$\begin{array}{l}\text { Restore patient's } \\
\text { functional ability to } \\
\text { pre-fracture state }\end{array}$} & $\begin{array}{l}\text { (Post-operative day 1) POD } 1 \text { mobilisation by } \\
\text { physiotherapist not tightly enforced }\end{array}$ & $\begin{array}{l}\text { POD } 1 \text { mobilisation by physiotherapist actively tracked and } \\
\text { enforced }\end{array}$ \\
\hline & $\begin{array}{l}\text { Patient outcome measures acquired only from } \\
\text { inpatient stay }\end{array}$ & $\begin{array}{l}\text { Expanded patient outcome measures acquired from both inpatient, } \\
\text { outpatient clinic and community hospital over } 1 \text { year post-surgery }\end{array}$ \\
\hline $\begin{array}{l}\text { Enhanced } \\
\text { information flow } \\
\text { and collection }\end{array}$ & $\begin{array}{l}\text { Manual workflow in documentation with } \\
\text { subsequent transcribing to electronic }\end{array}$ & $\begin{array}{l}\text { Electronic documentation in organizational electronic medical record } \\
\text { (EMR) system } \\
\text { Real-time best practice elements compliance dashboard }\end{array}$ \\
\hline
\end{tabular}

summarizes the key improvements achieved as a result of discussions with clinical core team and PDSA cycles.

The program office provided administrative governance in collaboration with clinical core teams, in order to establish and implement processes to improve care and reduce variation. The program office also facilitated implementation work by addressing barriers and applying quality improvement techniques, which included the development and implementation of appropriate clinical data collection tools, as well as EHR tool build-up and implementation. It was also responsible for planning and implementing the scaling up and spread of the ValuedCare model in $\mathrm{AH}$ and $\mathrm{CH}$.

For the strategic support, an oversight/steering committee was created including senior management from both and $\mathrm{CH}$. This platform was useful to review and provide on-going feedback on the progress of the $\mathrm{VC}$ program, and also for 'buy-in', as senior management from different organizations could come together to share concerns and chart directions. The oversight/steering committee also improved the functional integration between inter-hospital team members.

\section{Study design}

Non-randomized historical controlled study for patients aged 65 years and above treated for single and lowenergy hip fractures and undergone hip fracture surgery at AH. A baseline pre-intervention cohort was selected with admission dates between 1 January 2013 to 31 December $2013(n=351)$, while the VC cohort comprised of patient admissions between 1 December 2014 to 30 November $2015(n=329)$. Patients with multiple fractures, high-impact trauma and pathological fractures (metastasis, avascular necrosis) were excluded from the study.

\section{Objective}

To compare clinical outcomes, complications and healthcare utilization between baseline and ValuedCare groups.

\section{Statistical analysis}

Descriptive epidemiology was used to present demographic variables. Medians were compared using Kruskal-Wallis/Mann-Whitney $U$ test. Categorical variables were compared using chi-square test and interval variables using analysis of variance (ANOVA). Statistical calculations were performed using Stata 12.

\section{Results}

The demographic variables and baseline characteristics between pre-intervention and VC patients are reported in Table 2. The two groups had comparable representations in age, gender, race, pre-fracture residence and pre-fracture mobility.

Table 3 compares outcomes between baseline preintervention and VC populations. The inpatient, 30-day post-discharge and 12-month post-discharge mortality remained low at 1.2, 1.2 and $8 \%$ respectively; mortality data was obtained from a national registry. Forty-eight percent of the VC patients received surgical treatment within $48 \mathrm{~h}$ from admission, compared to $18.8 \%$ at baseline. Median time to surgery was reduced from 97 to 50 . $5 \mathrm{~h}$. Early access to surgery has shown to improve clinical outcomes in several international studies $[5,10]$. VC patients also had less acute inpatient complications as compared to the baseline pre-intervention cohort, in 
Table 2 Demographics and pre-morbidity profile baseline and ValuedCare groups

\begin{tabular}{|c|c|c|c|}
\hline Variable & Baseline $(n=351)$ & ValuedCare $(n=329)$ & $p$ value \\
\hline \multicolumn{4}{|l|}{ Age } \\
\hline Mean (SD) & $81.11(8.0)$ & $80.35(7.4)$ & 0.20 \\
\hline Median (min-max) & $82(65-99)$ & $81(65-102)$ & 0.85 \\
\hline Age group, $n(\%)$ & & & 0.013 \\
\hline $65-74$ & $91(25.9 \%)$ & $78(23.7 \%)$ & \\
\hline $75-84$ & $130(37.0 \%)$ & $157(47.7 \%)$ & \\
\hline$\geq 85$ & $130(37.0 \%)$ & $94(28.6 \%)$ & \\
\hline Gender, $n(\%)$ & & & 0.617 \\
\hline Females & 247 (70.4\%) & $225(68.4 \%)$ & \\
\hline Males & $104(29.6 \%)$ & $104(31.6 \%)$ & \\
\hline Race, $n(\%)$ & & & 0.557 \\
\hline Chinese & $265(75.5 \%)$ & $247(75.1 \%)$ & \\
\hline Malays & $49(14.0 \%)$ & $51(15.5 \%)$ & \\
\hline Indians & $20(5.7 \%)$ & $12(3.6 \%)$ & \\
\hline Others & $17(4.8 \%)$ & $19(5.8 \%)$ & \\
\hline Pre-fracture residence, $n$ (\%) & & & 0.77 \\
\hline Home & $332(94.6 \%)$ & $312(94.8 \%)$ & \\
\hline Nursing home & $14(4 \%)$ & $12(3.6 \%)$ & \\
\hline Sheltered home & $5(1.4 \%)$ & $5(1.5 \%)$ & \\
\hline Pre-fracture aid, $n(\%)$ & & & 0.152 \\
\hline No aid & $187(53.3 \%)$ & 197 (61\%) & \\
\hline Walking aid & $157(44.7 \%)$ & $118(36.5 \%)$ & \\
\hline Wheelchair & $7(2 \%)$ & $6(1.9 \%)$ & \\
\hline Bedbound & 0 & $1(0.3 \%)$ & \\
\hline Others & 0 & $1(0.3 \%)$ & \\
\hline Hypertension & $188(53.6 \%)$ & $228(69.3 \%)$ & $<0.001$ \\
\hline Hyperlipidaemia & 99 (28.2\%) & $145(44.1 \%)$ & $<0.001$ \\
\hline Diabetes mellitus & $130(37.0 \%)$ & $111(33.7 \%)$ & 0.379 \\
\hline Ischaemic heart disease (IHD) & $68(19.4 \%)$ & $51(15.5 \%)$ & 0.191 \\
\hline CCF/heart failure & $11(3.1 \%)$ & $12(3.6 \%)$ & 0.83 \\
\hline COPD/cold/asthma & $15(4.3 \%)$ & $17(5.2 \%)$ & 0.593 \\
\hline Peripheral vascular disease (PVD) & $13(3.7 \%)$ & $5(1.5 \%)$ & 0.095 \\
\hline Chronic renal failure & $50(14.2 \%)$ & $23(7.0 \%)$ & 0.03 \\
\hline
\end{tabular}

particular lower rates of delirium, pneumonia, urinary tract infections (UTI) and pressure sores. A reduction in 30-day and 180-day readmission rates for hip fracturerelated causes was noticed, although not statistically significant.

Comparisons of length of stay (LOS) between pre- and post-intervention data at $\mathrm{AH}$ and $\mathrm{AH}-\mathrm{CH}$ combined are summarized, respectively, in Figs. 2 and 3. A LOS of $\leq 10$ days for $\mathrm{AH}$ was taken as an internal reference target at the beginning of the program after a review of relevant literature [3, 22]. For AH (Fig. 2), the reduction in LOS was noticed to be statistically significant at a $p$ value $<0.001$. Figure 2 also shows a decreasing trend in $\mathrm{AH}$ monthly average LOS for a 1-year postintervention period ( $p$ value $<0.001, R^{2}=0.452$ ) and a corresponding increasing trend for a percentage of patients with LOS $\leq 10$ days ( $p$ value $<0.001, R^{2}=0.522$ )

Implementation of $\mathrm{VC}$ in $\mathrm{CH}$ began 1 year later than that in $\mathrm{AH}$; thus, pre- and post-intervention data for combined LOS were studied a year later as compared to $\mathrm{AH}$ data (Fig. 3). There was a significant reduction in combined $\operatorname{LOS}(\mathrm{AH}+\mathrm{CH})$ between baseline and postintervention population values $(p$ value $<0.001)$. A decreasing trend in monthly average LOS for a 1-year 
Table 3 Comparison of clinical outcomes between baseline and ValuedCare patients

\begin{tabular}{|c|c|c|c|}
\hline \multicolumn{4}{|l|}{ Mortality rates } \\
\hline Variable & Baseline $(n=351)$ & ValuedCare $(n=329)$ & $p$ value \\
\hline Index inpatient mortality, $n$ (\%) & $6(1.7 \%)$ & $4(1.2 \%)$ & 0.75 \\
\hline Variable & Baseline $\left(n=344^{*}\right)$ & ValuedCare $\left(n=325^{*}\right)$ & $p$ value \\
\hline Post-discharge 30 days mortality rate, $n$ (\%) & $1(0.3 \%)$ & $4(1.2 \%)$ & 0.2 \\
\hline Post-discharge 12 months mortality rate, $n(\%)$ & $27(7.8 \%)$ & $26(8.0 \%)$ & 0.94 \\
\hline \multicolumn{4}{|l|}{ Acute hospital inpatient complications } \\
\hline Variable & Baseline $(n=351)$ & ValuedCare $(n=329)$ & $p$ value \\
\hline Wound infection & $1(0.3 \%)$ & $0(0.0 \%)$ & 0.5136 \\
\hline Implant failure & $4(1.1 \%)$ & $1(0.3 \%)$ & 0.374 \\
\hline Delirium & $36(10.3 \%)$ & $13(4.0 \%)$ & 0.002 \\
\hline Acute retention of urine (ARU) & $53(15.1 \%)$ & $34(10.3 \%)$ & 0.067 \\
\hline Pneumonia & $45(12.8 \%)$ & $13(4.0 \%)$ & $<0.001$ \\
\hline Urinary tract infection (UTI) & $90(25.6 \%)$ & $16(4.9 \%)$ & $<0.001$ \\
\hline Pressure sore & $39(11.1 \%)$ & $1(0.3 \%)$ & $<0.001$ \\
\hline Deep vein thrombosis & $4(1.1 \%)$ & $8(2.4 \%)$ & 0.250 \\
\hline Pulmonary embolism & $5(1.4 \%)$ & $2(0.6 \%)$ & 0.452 \\
\hline Acute myocardial infarction & $8(2.3 \%)$ & $5(1.5 \%)$ & 0.580 \\
\hline Stroke & $4(1.1 \%)$ & $2(0.6 \%)$ & 0.687 \\
\hline Readmission rates & Baseline $\left(n=344^{*}\right)$ & ValuedCare $\left(n=325^{*}\right)$ & \\
\hline 30-day readmission (all cause), $n(\%)$ & $26(7.6 \%)$ & $31(9.5 \%)$ & 0.36 \\
\hline 30-day readmission (hip fracture related), $n$ (\%) & $17(4.9 \%)$ & $12(3.7 \%)$ & 0.42 \\
\hline 180-day readmission (all cause), $n$ (\%) & $74(21.5 \%)$ & $72(22.2 \%)$ & 0.84 \\
\hline 180-day readmission (hip fracture related), $n(\%)$ & $44(12.8 \%)$ & $27(8.3 \%)$ & 0.06 \\
\hline Time to surgery & Baseline $(n=351)$ & ValuedCare $(n=329)$ & \\
\hline Surgery within $48 \mathrm{~h}$ from time of decision to admit & $66(18.8 \%)$ & $158(48.0 \%)$ & $<0.001$ \\
\hline Time to surgery, h & & & $<0.001$ \\
\hline Mean (SD) & $119.2(86.3)$ & $70.63(64.4)$ & \\
\hline Median (min-max) & $97(11-499)$ & $50.5(0.11-638)$ & \\
\hline
\end{tabular}

*Inpatient deaths and discharge against advice cases are taken out of the analysis

post-intervention period ( $p$ value $<0.001, R^{2}=0.32$ ) was also noticed.

\section{Discussion}

As Michael Porter describes, value cannot be understood at the level of a hospital, a care site, a specialty, or an intervention. Value is created in caring for a patient's medical condition over the full cycle of care [21]. VC program attempts to implement system level transformation to measure health outcomes over disease life cycle, including functional outcomes, and cost of care over care continuum across institutions. The focus thus shifts to providing evidence-based and consistent patient care to achieve better outcomes over the entire cycle of care, instead of merely introducing cost containment measures within a particular institution. VC program aims to totally study the overall healthcare ecosystem (rather just hospital-based services), so that true efficiencies are achieved to create value for patients (e.g. right siting of services and elimination of non-value adding services). VC BPEs include preventive interventions such as osteoporosis treatment, secondary fall prevention, functional rehabilitation and caregiver training. It also measures longer term functional health outcomes such as longitudinal Modified Barthel's Index (MBI)/Barthel and Functional Independence.

We compared the results of our VC program with the published results of international Geriatric Fracture Centers (GFCs) in terms of LOS, mortality and morbidity data (Table 4). Among the models compared, ValuedCare's mortality rates of 1.2 and $8 \%$ were the lowest for, respectively, intra-hospital rates and at 1 year follow-up. One-year mortality for surgically managed hip fracture cases has been reported in some overseas centres to be 


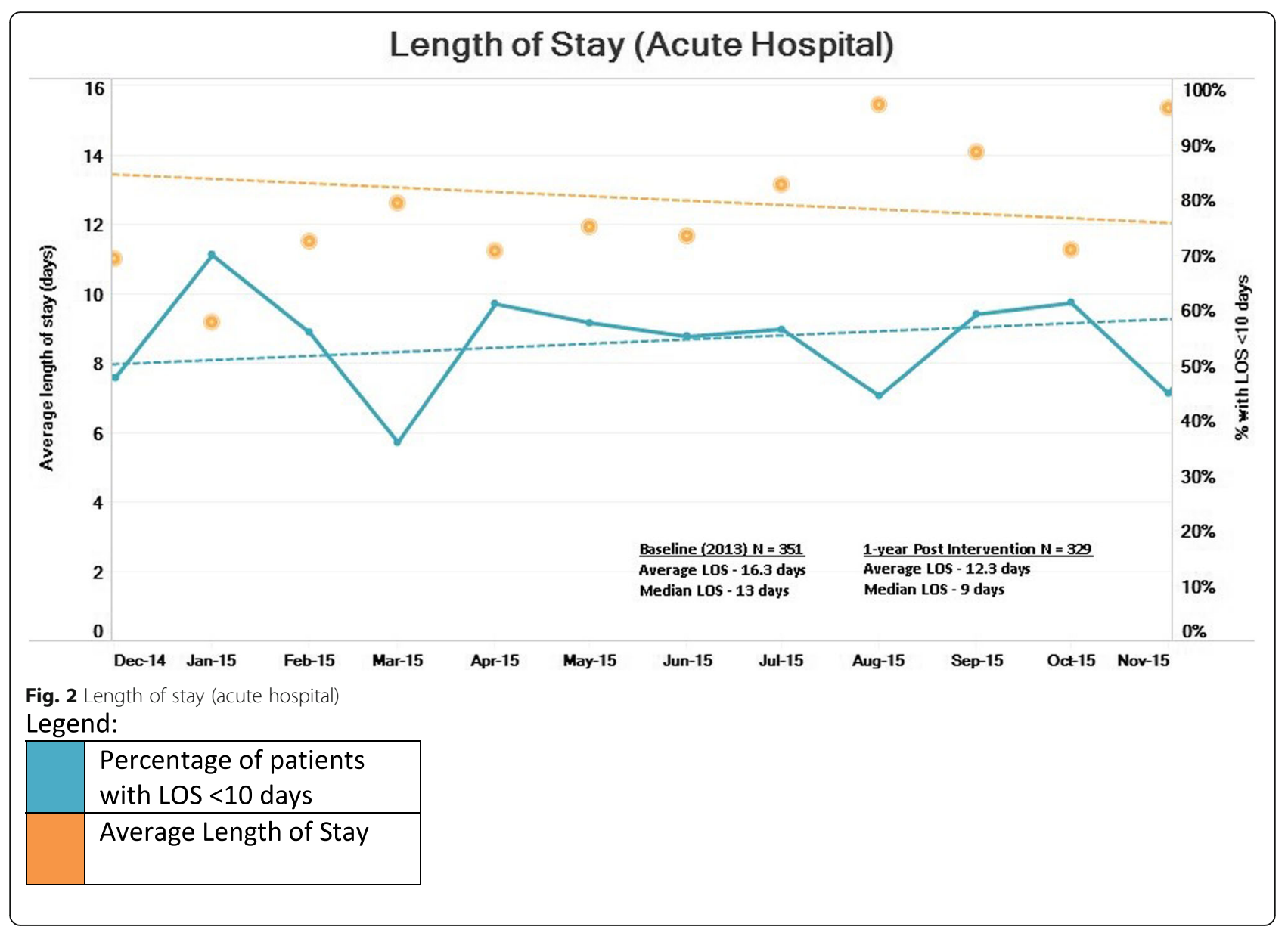

as high as 30\% [23]. Our 30-day readmission rates are also among the lowest. It was noticed in the international literature that LOS can vary between 4.2 and 15.8 days. Several factors affect LOS, such as differences in models of step-down care available in different countries, efficiency of referral mechanisms, level of integration, as well as availability of step-down or rehabilitation care beds. In Rochester [24], where the LOS is the shortest (4.2 days), patients are moved to their nursing facility rehabilitation beds by the third post-operative days. In most centres, including Singapore, patients have to wait for an available bed in rehabilitation hospital or $\mathrm{CH}$. Under the $\mathrm{VC}$ program, $\mathrm{AH}$ and $\mathrm{CH}$ teams worked together to streamline the inter-hospital transfer process and eliminate unnecessary administrative steps. Referral requests were raised early (post-operative day 2), and specific referral and acceptance criteria were delineated and made transparent to the clinical team. $\mathrm{CH}$ rehabilitation team reviewed the patient at $\mathrm{AH}$ and hastened the transfer process if patients met the predefined criteria.

It was noticed that after VC implementation, the average length of stay (ALOS) at $\mathrm{AH}$, as well as combined
LOS $(\mathrm{AH}+\mathrm{CH})$, has shown consistent significant improvement. ALOS at AH decreased from 16.3 to 12. 3 days (median 13 to 9 days), while combined ALOS $(\mathrm{AH}+\mathrm{CH})$ showed a reduction from 51.6 to 43.3 days (median 46 to 39 days). Reduction in combined length of stay is of relevant importance as it indicates that this result was achieved with process redesign instead of shifting the burden of care to the next healthcare setting. Reductions in LOS, along with reduction in hip fracturerelated admissions up to 6 months (12.8 to $8.3 \%$ ), result in savings in hospital bed days. This is significant especially in the context of rising demand for hospital beds and costs with a growing ageing population.

In both $\mathrm{AH}$ and $\mathrm{CH}$, rehabilitation doctors, nurses, therapists and medical social workers work together to speed up the recovery process. Early active walking exercise and post-discharge rehabilitation by community nurses and therapists play an important role in shortening the need for inpatient treatment. The regular assessments of the mental and functional state can help to enhance the recovery of patients. The medical social workers identify social or financial problems that may complicate the discharge and activate available resources 


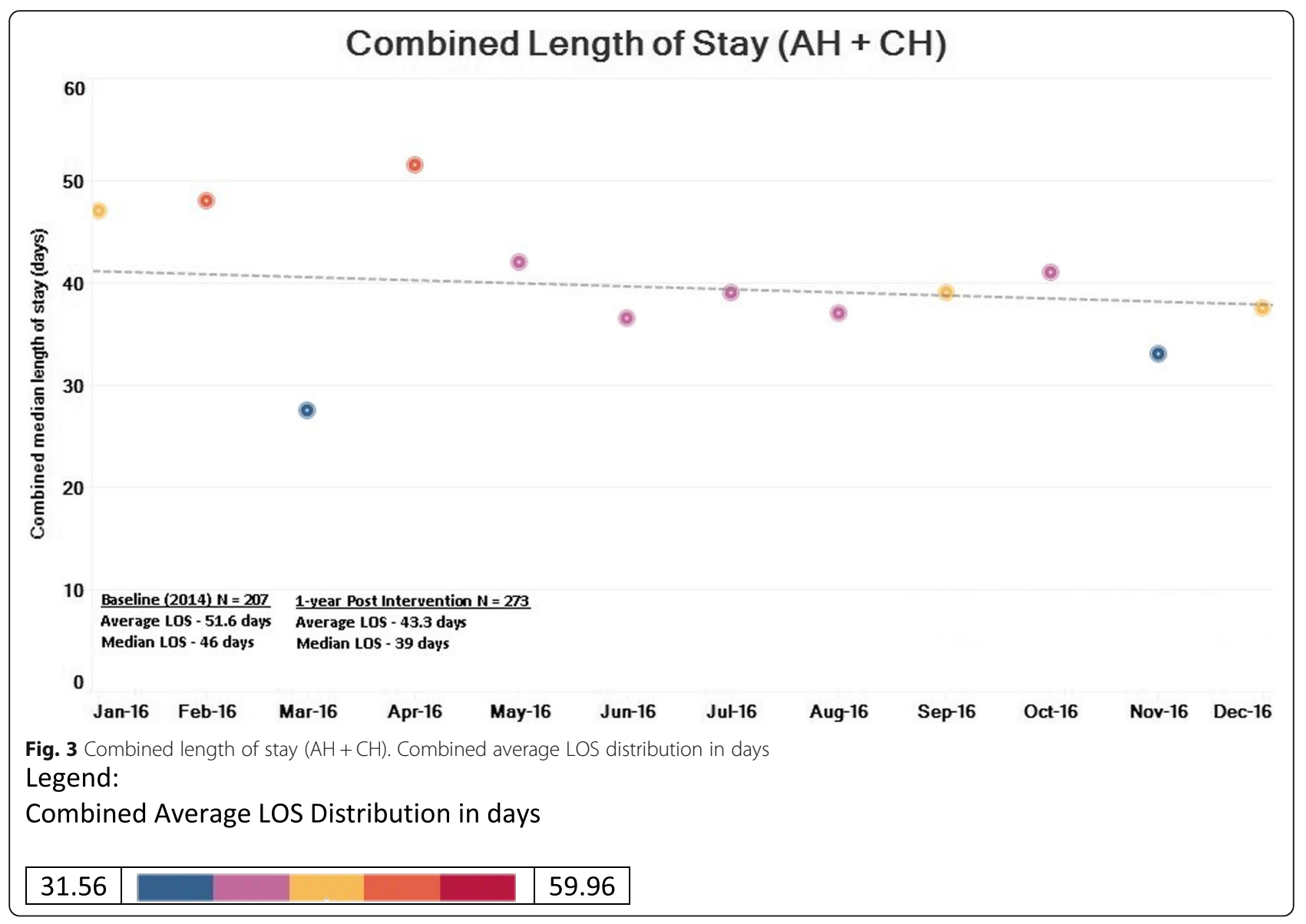

to help them. The overall shortened hospital stay reflects the effectiveness and cooperation with this multidisciplinary approach.

$\mathrm{VC}$ results are consistent with our hypothesis that with implementation of BPEs and minimizing unwarranted variations in care, health and utilization outcomes can be improved. The team acknowledges the scope for further improvements in the combined LOS in $\mathrm{AH}+\mathrm{CH}$. We are working towards achieving our target of getting at least $70 \%$ VC cases operated within $48 \mathrm{~h}$ from hospital admission. Also, detailed analysis of functional outcomes, quality of life (QOL) and interventions for secondary prevention of falls and fractures will be performed within the next phase of $\mathrm{VC}$ program.

\section{Conclusion}

The implementation of VC hip fracture program has enabled consistent delivery of high-quality, reliable and comprehensive evidence-based care for hip fracture patients. This has been further strengthened by successful change management and interdisciplinary collaboration within the organization. Efforts are on-going to sustain these best practices and augment gains. The program will be scaled to include other medical conditions using VC methodology which could, through the application of process redesign, implement multiple evidence-based medical practices across the continuum of care in an integrated delivery system and deliver highquality reliable care.

Table 4 Comparison of length of stay, morbidity and mortality data of various geriatric hip fracture programs [8, 23-26]

\begin{tabular}{llllll}
\hline & $\begin{array}{l}\text { Rochester model } \\
{[24]}\end{array}$ & $\begin{array}{l}\text { Innsbruck model } \\
{[27]}\end{array}$ & $\begin{array}{l}\text { Singapore } \\
\text { ValuedCare }\end{array}$ & $\begin{array}{l}\text { Hong Kong } \\
\text { model [28] }\end{array}$ & $\begin{array}{l}\text { National Hip Fracture } \\
\text { Database (UK) [8, 22] }\end{array}$ \\
\hline Length of stay, days & 4.2 & 11.3 & 9 & 6.4 & 15.8 \\
30-day readmission & 9.8 & 5.2 & 3.7 & 15 & 11.8 \\
Hospital mortality rates, \% & 1.6 & 3.1 & 1.2 & 1.25 & 8.2 \\
1-year mortality, \% & 21.2 & Not available & 8 & $16.4-22.4$ & 19.3 \\
\hline
\end{tabular}




\section{Limitations}

Non-randomized historical controlled study design has inherent limitations, but a randomized control trial presents ethical concerns as the 'intervention' aim consists of implementing best practice elements. The implementation of $\mathrm{VC}$ program in $\mathrm{CH}$ was a year later as compared to that in $\mathrm{AH}$; thus, pre- and post-intervention data for $\mathrm{CH} \mathrm{LOS}$ was studied a year later as compared to $\mathrm{AH}$ data. Readmission data were specific to $\mathrm{AH}$ as we do not have data for readmissions to other hospitals.

\section{Abbreviations \\ AH: Acute hospital; ALOS: Average length of stay; CGH: Changi General Hospital; $\mathrm{CH}$ : Community hospital; EHA: Eastern Health Alliance; EHR: Electronic health records; MBI: Modified Barthel's Index; MOH: Ministry of Health Singapore; QI: Quality improvement; RHS: Regional Health System; SACH: St. Andrews Community Hospital; VC: ValuedCare}

\section{Acknowledgements}

We are thankful to the CGH VC Program Office and the Departments of Geriatric Medicine, Orthopaedic Surgery, Case Management, Nursing, Accident and Emergency, Anaesthesiology and Health Services Research as well as to the staff and senior management from Changi General Hospital, Eastern Health Alliance, Saint Andrew's Community Hospital and Geisinger Health System for their support for this initiative.

\section{Availability of data and materials}

Authors have attempted to keep the information lucid with appropriate explanations. However, upon queries on data and materials, the datasets used and/or analyzed during the current study are available with the corresponding author.

\section{Declarations}

The manuscript has not been published elsewhere, and it is also not currently under consideration for publication by another journal.

\section{Authors' contributions}

CM was responsible for the data collation as well as the manuscript preparation. DL provided guidance for the study design. SG, AL, LT, CS, HL and EG were involved in the manuscript revision. EL provided supervision as well as overall strategic direction for the study and VC program. LS performed the statistical analysis for the study. All authors read and approved the final manuscript.

\section{Ethics approval and consent to participate}

The audit and secondary analysis of this dataset was in keeping with national guidelines as stipulated by Singapore Ministry of Health under the Private Hospitals and Medical Clinics Act that requires licensed healthcare establishments to evaluate internal quality improvement procedures on a continuing basis. Ethical approval was obtained by the Singhealth Centralised Institutional Review Board for the study in Changi General Hospital as well as St. Andrews Community Hospital. No patients were contacted for the study, and the need for a written consent was formally waived by the ethics committee.

\section{Competing interests}

The authors declare that they have no competing interests.

\section{Publisher's Note}

Springer Nature remains neutral with regard to jurisdictional claims in published maps and institutional affiliations.

\section{Author details}

${ }^{1}$ Clinical Services, Level 2, Changi General Hospital, 2 Simei Avenue 3, Singapore 529889, Singapore. ${ }^{2}$ ValuedCare Program Office, Changi General Hospital, Singapore, Singapore. ${ }^{3}$ Department of Geriatric Medicine, Changi General Hospital, Singapore, Singapore. ${ }^{4}$ Department of Orthopaedics, Changi General Hospital, Singapore, Singapore. ${ }^{5}$ Executive Office, St. Andrews
Community Hospital, Singapore, Singapore. ${ }^{6}$ Medical Services, St. Andrews Community Hospital, Singapore, Singapore. ${ }^{7}$ Health Services Research, Changi General Hospital, Singapore, Singapore. ${ }^{8}$ Executive Office, Changi General Hospital, Singapore, Singapore.

Received: 11 December 2017 Accepted: 24 April 2018

Published online: 30 May 2018

\section{References}

1. Johnell O, Kanis JA. An estimate of the worldwide prevalence, mortality and disability associated with hip fracture. Osteoporos Int. 2004;15:897-902.

2. Grigoryan $\mathrm{KV}$, Javedan $\mathrm{H}$, Rudolph JL. Orthogeriatric care models and outcomes in hip fracture patients: a systematic review and meta-analysis. J Orthop Trauma. 2014;28:49-55.

3. National Institute for Health and Care Excellence. Quality Standards for Hip Fracture 2012. Available from: http://www.nice.org.uk. Accessed 10 June 2017.

4. Khasraghi FA, Christmas C, Lee EJ, et al. Effectiveness of a multidisciplinary team approach to hip fracture management. J Surg Orthop Adv. 2005;14(1):27-31.

5. National Institute for Health and Clinical Excellence, The management of hip fracture in adults. London: Clinical guideline; 2011. Available at www.nice.org. uk/guidance/cg124/evidence/full-guidance-183081997. Accessed 8 May 2018.

6. Chesser T, Kelly M. Management of hip fractures in the elderly. Surg e Oxf Int Ed. 2013:31:456-9.

7. Riemen AHK, Hutchison JD. The multidisciplinary management of hip fractures in older patients. Orthop Trauma. 2016;30(2):117-22.

8. Ramason R, Chong MS, et al. Innovations in hip fracture care: a comparison of geriatric fracture centers. JAMDA. 2014;15:232-3.

9. Mithal A, Dhingra V, Lau E. The Asian audit: epidemiology, costs and burden of osteoporosis in Asia. Switzerland: International Osteoporosis Foundation. 2009;2009:1-60.

10. Smith T, Pelpola $K$, et al. Pre-operative indicators for mortality following hip fracture surgery: a systematic review and meta-analysis. Age Ageing. 2014;0:1-8.

11. Tsung WC, et al. Integrated care pathway for hip fractures in a subacute rehabilitation setting. Ann Acad Med Singap. 2013;42:579-84.

12. Yong D. Role of community hospitals in care of the elderly in Singapore. Singapore Fam Physician. 2002;28(4):44-7.

13. Shum E, Lee CE. Population-based healthcare: the experience of a regional health system. Editorial: Annals Academy of Medicine Singapore. 2014;43(12):564-5.

14. Langley GL, Nolan KM, Nolan TW, et al. The improvement guide: a practical approach to enhancing organizational performance. San Francisco: Jossey-Bass; 1996

15. Nolan TN, Resar R, Haraden C, et al. Improving the reliability of health care. Innovation series white paper. Cambridge: Institute of Health Improvement; 2004

16. Berry SA, Doll MC, et al. ProvenCare: quality improvement model for designing highly reliable care in cardiac surgery. Qual Saf Health Care. 2009;18:360-8.

17. Slotkin JR, Casale AS, et al. Reengineering acute episodic and chronic care delivery: the Geisinger Health System experience. Neurosurg Focus. 2012;33(1):16.

18. Lee TH, Bothe A, Steele GD. How Geisinger structures its physicians' compensation to support improvements in quality, efficiency, and volume. Health Aff. 2012:31(9):2068-73.

19. Paulus RA, Davis K, Steele GD. Continuous innovation in health care: implications of the Geisinger experience. Health Aff. 2008;27(5):1235-45.

20. Kotter JP. Leading change: why transformation efforts fail. Harv Bus Rev. 1995:73(2):59-67.

21. Porter ME. What is value in health care? NEJM. 2010;363(26):2477-81.

22. Health Quality Improvement Partnership. National Hip Fracture Database. National Report 2016. Available at: http://www.nhfd.co.uk/. 2016report. Accessed October 26, 2017.

23. Schnell S, Friedman SM, Mendelson DA, et al. The 1-year mortality of patients treated in a hip fracture program for elders. Geriatr Orthop Surg Rehabil. 2010:1:6-14.

24. Kates SL, Mendelson DA, Friedman SM. Co-managed care for fragility hip fractures (Rochester model). Osteoporos Int. 2010;21:621-5.

25. Kates SL, Blake D, Bingham KW, et al. Comparison of an organized geriatric fracture program to United States government data. Geriatr Orthop Surg Rehabil. 2010;1:15-21. 
26. Friedman SM, Mendelson DA, Kates SL, et al. Geriatric co-management of proximal femur fractures: total quality management and protocol-driven care result in better outcomes for a frail patient population. J Am Geriatric Soc. 2008:56:1349-56.

27. Kammerlander C, Gosch M, Blauth M, et al. The Tyrolean Geriatric Fracture Center: an orthogeriatric co-management model. Z Gerontol Geriatr. 2011;44:363-7.

28. Lau TW, Leung F, Siu D, et al. Geriatric hip fracture clinical pathway: the Hong Kong experience. Osteoporos Int. 2010;21:627-36.

Ready to submit your research? Choose BMC and benefit from:

- fast, convenient online submission

- thorough peer review by experienced researchers in your field

- rapid publication on acceptance

- support for research data, including large and complex data types

- gold Open Access which fosters wider collaboration and increased citations

- maximum visibility for your research: over $100 \mathrm{M}$ website views per year 